\title{
Mudança e Continuidade: A Formulação Jamesiana do Pensamento como um Fluxo
}

\section{Change and Continuity: The Jamesian Formulation of Thought as a Stream}

\author{
Paulo Gilberto Bertoni* \& Débora Cristina Morato Pinto \\ Universidade Federal de São Carlos, São Carlos, Brasil
}

\begin{abstract}
Resumo
Este artigo discute o projeto de psicologia apresentado por William James no final do século XIX. A exposição tem como pano de fundo o debate que James estabelece com outras teorias psicológicas, particularmente o associacionismo, e destaca suas divergências em relação a elas. As diferenças entre a psicologia jamesiana e o associacionismo são apresentadas através da oposição da noção de pensamento, entendido como um fluxo, e a concepção associacionista do estado mental como composição de elementos independentes. O produto da análise é a crítica ao associacionismo com base na tese da unidade intrínseca de cada pensamento e a indicação das conseqüências teóricas e metodológicas dessa nova formulação.

Palavras-chave: William James; pensamento; fluxo; associacionismo.

Abstract

This article discusses the project for psychology presented by William James at the end of the nineteenth century. The exposition is concentrated on James' debate with other psychological theories, notably associationism, and points out his criticism to them. The differences between Jamesian psychology and associationism are shown through the opposition of the concept of thought as a stream and associationist comprehension of mental state as a compound of independent elements. The product of this analysis is the criticism of associationism based on the intrinsic unity of each thought and the indication of the methodological and theoretical implications of this new conception.

Keywords: William James; thought; stream; associationism.
\end{abstract}

O livro The Principles of Psychology de William James, publicado em 1890, é um dos principais textos da história da Psicologia. Sua importância se dá tanto pela sistematização que traz das informações científicas existentes à época de sua publicação quanto por suas contribuições para a estruturação de um programa conceitual consistente para o desenvolvimento da nova ciência. $\mathrm{O}$ vigor dessa análise conceitual pode ser identificado não só pela influência do tex to ao longo de toda história da disciplina, mas, também, pelo interesse que despertou - e continua despertando entre os filósofos. Alguns problemas são colocados de forma tão incisiva que acabam conduzindo o autor norte-americano para uma reflexão propriamente filosófica (James, 1909/ 1998, 1912/1976).

O projeto da psicologia jamesiana pode ser compreendido, em grande medida, por sua oposição às tradições com as quais se depara no final do século XIX e como tentativa de superar as dificuldades apresentadas por essas escolas. Para James (1890/1952), é fundamental que a experiência psi-

\footnotetext{
* Endereço para correspondência: Paulo Gilberto Bertoni/Débora Cristina Morato Pinto: Universidade Federal de São Carlos, Departamento de Filosofia, Via Washington Luís, km 235, Bairro Monjolinho, São Carlos, SP, 13565-905. Fone/fax: (16)3351-8366. E-mail: pgbertoni@hotmail.com e deboramp@power.ufscar.br
}

cológica seja tratada em toda sua complexidade sem recorrer a simplificações ou a princípios explicativos que transcendam de alguma forma a própria experiência concreta. Uma psicologia com o mínimo de especulações metafísicas, fundada prioritariamente na descrição de seus fenômenos, é a diretriz de sua teoria.

Essa orientação geral está presente na maneira pela qual James (1890/1952) apresenta o objeto da Psicologia, através da noção de pensamento, particularmente na oposição que estabelece entre sua proposta e uma das escolas contemporâneas a ele, o associacionismo. O mérito dessa doutrina, segundo James, é ter conduzido a disciplina para um universo empírico, mas sua principal dificuldade foi não ser capaz de garantir a unidade de cada estado mental e entre os diferentes estados, gerando com isso problemas práticos e teóricos. O objetivo deste artigo é investigar o debate de James com o associacionismo no que diz respeito à caracterização do objeto da Psicologia, particularmente o estabelecimento da unidade intrínseca a todo estado mental e à continuidade inerente aos diversos estados mentais dentro de uma própria consciência.

A constatação da unidade intrínseca a qualquer estado mental fundamenta a crítica ao reducionismo da psicologia associacionista. A questão da unidade entre os estados, 
garantida pelo reconhecimento dos estados mentais transitivos, tem influência direta no próprio âmbito de investigação da disciplina, uma vez que, ao chamar atenção para um aspecto da vida mental negligenciado por alguns de seus contemporâneos, James (1890/1952) acaba propondo um alargamento do objeto de estudo da Psicologia. Os estados transitivos permitem estabelecer a continuidade - e com ela a unidade - e extrapolam o âmbito da psicologia de William James, servindo também como fundamento para o desenvolvimento posterior do Empirismo Radical (James, 1912/ 1976). No entanto, a maneira de tratar esses estados oferece um desafio particular não só dentro de sua obra como para a própria Psicologia.

\section{O Pensamento na Psicologia Jamesiana}

A Psicologia é caracterizada como "o estudo da vida mental, de seus fenômenose das condições [grifos nossos】 de ocorrência desses fenômenos" (James, 1890/1952, p. 1). A expressão fenômenos indica sua ênfase no tratamento empírico, um interesse pela análise da experiência concreta. Por condições devese entender o fundamento biológico de toda atividade mental (Heidbreder, 1933/1975): todo estado mental está vinculado a um estado corporal, embora não possa ser reduzido a ele; coloca-se, portanto, o aspecto orgânico da vida mental como determinante das características dos seus fenômenos. O critério de decisão sobre como atribuir o predicado mentalé seu aspecto teleológico (Giorgi, 1992); isto é, a possibilidade de um ser "perseguir objetivos futuros e escolher os meios para atingi-los" (James, 1890/1952, p. 5).

$\mathrm{O}$ ponto de partida ideal para fugir aos problemas metafísicos atrelados aos conceitos utilizados tradicionalmente pela Psicologia é, segundo James (1890/1952), a utilização de uma expressão que simbolize qualquer estado de consciência, "independentemente de sua qualidade particular ou função cognitiva" (James, p. 121). Este tipo de estratégia faz com que os termos empregados não sejam, em princípio, tão importantes: o objetivo do autor é sempre colocar o leitor em contato com algum fenômeno específico, não está em seu horizonte nenhum tipo de demonstração conceitual estrita ${ }^{1}$. No entanto, tal procedimento pode gerar, em alguns momentos, uma dificuldade para identificar, de forma mais precisa, o sentido de alguns termos.

O termo Pensamento ${ }^{2}$ (Thought) é escolhido, inicialmente, por sua aparente neutralidade. "Se pudéssemos dizer em inglês 'it thinks' da mesma forma que dizemos 'it rains' ou 'it blowe', nós estaríamos colocando a questão da maneira mais simples e com o mínimo de suposição" (James, 1890/1952, p. 146); com a vantagem adicional de "sugerir imediatamente a onipresença da cognição (ou referência a um objeto

\footnotetext{
${ }^{1}$ A significação da linguagem utilizada por James é estabelecida, em diversas situações, em seu "processo de aplicação à experiência consciente" (Myers, 1992, p. 57). Uma espécie de roteiro para que o leitor depare, em sua própria experiência, com o fenômeno tratado. Por esse motivo, ao longo desse artigo, principalmente por questões de estilo, algumas expressões como pensamento, estado mental, estado de consciência serão utilizadas quase como sinônimos.

${ }^{2}$ Ao longo do texto, pensamento (com letra minúscula) será utilizado para indicar algum estado mental específico e Pensamento para fazer referência à atividade mental como um todo.
}

que não o próprio estado mental)" (James, p. 122); ou seja, há uma tentativa de romper os limites do próprio estado: todo pensamento é pensamento de. Há, contudo, uma espécie de inadequação do termo para descrever estados atuais de dor ou prazer, como, por exemplo, a dificuldade em dizer "pensamento de uma dor de dente". Por essa razão, James utiliza paralelamente a expressão feeling ${ }^{3}$, destacando nela também um sentido geral.

A estratégia descritiva adotada é evidenciada pela exposição das particularidades do Pensamento. Essas características estão sintetizadas em um capítulo dos Princípios intitulado O Fluxo do Pensamento e servem como um esquema dos principais aspectos que serão desenvolvidos ao longo da obra. A primeira característica do pensamento é tender a uma forma pessoal. A segunda é estar em constante mudança. A terceira é ser sensivelmente contínuo. A quarta é ser cognitivo e a quinta é ser seletivo. Todo pensamento, portanto, faz parte de uma rede de relações com outros pensamentos em uma consciência pessoal e se reconhece como parte dela; é único; não apresenta cisões ou rupturas em suas relações com outros pensamentos; é capaz de conhecer e está sempre mais interessado em algum aspecto de seu conteúdo que em outro. Cada um dos enunciados serve de guia para aspectos importantes tanto para a obra de James (1890/1952) como para a Psicologia de maneira geral. A personificação do pensamento aponta para o interesse na noção de self; sua dinâmica, para o problema da transformação e da repetição da experiência; a continuidade, para o problema de como estabelecer o vínculo entre pensamentos tão distintos de um mesmo sujeito; a cognição, para o estabelecimento da relação entre sujeito e objeto ou entre o pensamento e a coisa conhecida; e a seleção, destaca os mecanismos que operam no recorte de certos aspectos de seu conteúdo.

\section{Dinâmica e Estabilidade}

$\mathrm{O}$ associacionismo ${ }^{4}$ afirma, essencialmente, a formação sintética dos estados mentais complexos a partir de átomos de percepção, que são, em última análise, sensações (James, 1890/1952). Essa síntese é possível graças a um mecanismo de composição e recombinação dos elementos iniciais. "Os sentidos inicialmente tratam com idéias particulares, preenchendo o gabinete vazio, e a mente se familiariza com algumas

\footnotetext{
${ }^{3}$ Esse termo apresenta uma dificuldade especial de tradução, pois oscila entre os termos sensação e sentimento, aproveitando o seu aportuguesamento, ele será mantido.

${ }^{4}$ A caracterização precisa da tradição associacionista é um problema específico de investigação tanto para os historiadores da Psicologia quanto para os interessados na obra do psicólogo norte-americano. A complexidade do tema e os objetivos delineados aqui - a exposição propriamente da psicologia jamesiana - conduzem à opção por uma descrição sucinta da escola com ênfase nos pontos destacados por James (1890/1952) e seguindo seu próprio roteiro de interlocutores, para os temas que são de interesse específico para este artigo. Com isso, deixa-se em aberto um problema de pesquisa e atribui-se a responsabilidade por essa leitura do associacionismo a ele próprio. É importante ressaltar, também, que não se trata de discutir o associacionismo na obra dos autores escolhidos, mas sim, através de seus textos, reconstruir o itinerário proposto por James e esclarecer as teses centrais da tradição, a fim de tornar esta exposição mais clara, talvez sacrificando com isso a coesão da descrição em prol de sua utilidade didática. A análise se concentra no empirismo inglês e tem, particularmente, dois objetivos: a crítica ao estado mental complexo como composição e o problema da sucessão descontínua no pensamento.
} 
delas, depositando-as na memória e designando-as por nomes" (Locke, 1706/1973, p. 154). E “quando o entendimento já está abastecido de idéias simples, tem o poder para repetir, comparar e uni-las numa variedade quase infinita, formando à vontade novas idéias complexas" (Locke, p. 170).

As idéias, simples ou complexas, são os elementos que se apresentam à consciência. A transição entre uma idéia e outra é tratada como um encadeamento no qual cada segmento não guarda nenhuma relação inerente com o outro. Segundo James (1890/1952), o filósofo Thomas Hobbes foi o "primeiro a formular o problema da sucessão no nosso pensamento" (James, p. 388), ao concebê-lo como um discurso mental - em alusão ao discurso verbal (Hobbes, 1651/1974) - uma seqüência ou cadeia de representações cuja gênese última se encontra na experiência. O mais importante na sucessão do pensamento, afirmação que James atribui a David Hume, é o fato dele ser "composto por partes separadas, não podendo ser um fluxo sensivelmente contínuo" (James, p. 154). O problema da concepção do estado mental complexo como composição será tratado nesta seção do texto e a questão da sucessão será retomada na próxima.

A construção de percepções ou estados complexos dá-se pela composição e recombinação de elementos fundamentais. As possibilidades de composição e recombinação estão fundamentadas em dois pressupostos. Se a percepção complexa é uma composição, isto quer dizer que ela é fragmentada ou formada por elementos independentes; um "mosaico de sensações” (James, 1899/1983c); ou seja, a idéia de "maçã" é a soma das idéias de cheiro, cor e forma que a compõem. Recombinar implica a possibilidade de repetir o mesmo em situações diferentes (James, 1890/1952), formando novas relações, o que exige a formulação dos elementos como cópias ou representações (estáveis, constantes, inalteradas; como as peças de um quebra-cabeça). Em outras palavras, a constância dos elementos é a condição necessária para a recombinação. Tal formulação permite que estados complexos sejam reduzidos a suas porções mais simples, sem nenhuma perda, já que a complexidade significa justaposição ou conexão de unidades sem nenhum vínculo essencial.

A experiência cotidiana parece corroborar essa perspectiva. "As sensações que temos com o mesmo objeto, não são as mesmas? A mesma tecla do piano pressionada com a mesma intensidade não nos faz ouvir do mesmo modo?" (James, $1890 / 1952$, p. 150). No entanto, a suposição da repetição da mesma sensação baseia-se, segundo James, em uma confusão entre as sensações, tomadas como fatos subjetivos, e o que elas permitem conhecer sobre o mundo ou as "realidades que elas revelam” (James, p. 150); isto é, entre a experiência como tal e o que ela informa sobre o mundo. O esforço do autor será em demonstrar que o que se repete é o mesmo objeto, entendido como "um conjunto de sensações" (James, 1879/1983a), como, por exemplo, a mesma nota musical; as sensações ou, de maneira mais ampla, o próprio pensamento, estão em constante mudança.

James (1890/1952), como já destacado, se propõe a contestar a tese empirista baseado também na experiência, criticando, em primeiro lugar a necessidade de postular um caráter absoluto para a sensação - conseqüência retirada da tese da repetição - e de tomar o sujeito como um mero receptor. Um exame mais acurado de situações também corriqueiras parece mostrar que nenhuma sensação, como, por exemplo, a sensação visual, é experimentada isoladamente; ela depende de vários fatores, dentre eles, a iluminação e a localização do objeto em relação ao observador. A intensidade do brilho da Lua, por exemplo, quando observada à noite - isto é, contra um fundo escuro - é diferente se comparada com sua observação durante o dia; a concorrência com a luminosidade do dia faz com que a Lua, tão majestosa durante a noite, ofereça uma impressão de algo opaco. Isto quer dizer que determinada sensação, neste caso o brilho, afeta o observador dependendo de sua razão ou proporção no conjunto com outras em um dado momento ${ }^{5}$ e que, portanto, varia de acordo com a variação do ambiente; ou seja, depende da maneira pela qual o objeto em questão está inserido em um contexto mais amplo ${ }^{6}$. A variação na sensação pode ser atestada, ainda, pelas modificações nas próprias condições do organismo: "a sensibilidade máxima do olho à luz é no momento de sua primeira exposição ... Uma longa noite de sono nos faz ver as coisas com o dobro do brilho que no decorrer do dia” (Fick, citado por James, p. 151).

Os casos analisados até este momento tratam apenas do ambiente, no sentido físico, e do organismo, do ponto de vista fisiológico, como se a sensação fosse pura e não misturada nas coisas; isto é, como se uma sensação fosse um processo totalmente destituído de traços de memória e conotações emocionais. E mesmo nessas situações, há indícios contra a possibilidade de repetição de uma mesma situação, pois ela necessitaria de um ambiente e de um organismo não modificados ${ }^{7}$. Contudo, a variação torna-se mais destacada quando as sensações são tomadas em relações mais amplas.

A sensação depende de seu contexto, não apenas das condições antecedentes, mas também dos fatores que se seguem a ela. Uma determinada nota musical, quando ouvida após um barulho intenso, produz um resultado diferente daquele identificado quando rompe um período de silêncio; se sua execução é feita em uma escala ascendente, o efeito com as outras notas é diferente daquele da escala descendente; se ela faz lembrar uma melodia triste ou está relacionada a um momento alegre, acarreta sentimentos distintos. Ou seja, uma sensação é o todo das relações que ela encerra; em uma palavra, é uma relação. O “mesmo” é constantemente apresentado em situações distintas, isto é, em novas relações, visto por outro ângulo, e, por isso, oferece novas percepções. Portanto, não se deve confundir a experiência do mesmo

\footnotetext{
5 James (1890/1952) trata especificamente da relatividade das sensações no capítulo XVII (Sensation, pp. 457-459).

${ }^{6}$ Em outro texto, James (1889/1983c) distingue dois aspectos no ato de perceber o foco, aquilo que está no centro da percepção, e as margens. Ver particularmente o capítulo II.

7 É importante ressaltar que James atribui um papel significativo para as condições fisiológicas em sua relação com a vida mental. E, admitindo-se a transformação constante do organismo, as condições mentais correlacionadas a tal estado jamais voltariam a ocorrer.
} 
com a mesma experiência; isto é, o objeto do pensamento com o próprio pensamento.

$\mathrm{O}$ aspecto único de todo estado mental e, conseqüentemente, a expressão de sua transformação, pode ser melhor evidenciado em situações mais complexas: a mulher amada perde o encanto, o livro favorito agora é sinônimo de tédio. James (1890/1952) destaca na experiência uma fonte de transformação constante, cujo resultado interfere em cada nova percepção, formando um processo contínuo de renovação. "A experiência nos remodela a cada instante, e nossa reação mental a cada coisa dada é realmente o resultado de nossa experiência do mundo todo até aquele instante” (p. 152). Em outras palavras, a experiência - inclui-se aí a experiência consigo mesmo - é sempre diferente, na medida em que, tanto o sujeito quanto o ambiente se modificam, não sendo possível repetir determinado arranjo; isto significa dizer que o pensamento está em constante mudança.

Ao contextualizar a sensação, James (1890/1952) relaciona-as intrinsecamente e, com isso, ataca seu caráter absoluto - critério necessário para que ela pudesse compor estados distintos. Ademais, como a intrincada cadeia de relações (condições do organismo, estimulação ambiental, experiências anteriores etc.) varia, não há possibilidade de recorrência de uma sensação idêntica em momentos distintos. A partir desse exame pode-se dizer não só que a noção associacionista dos estados mentais como mera composição é inconsistente, mas também desnecessária: não é preciso explicar como se relaciona aquilo que já é dado como relação; ou seja, que não pode ser concebido de outra maneira; a unidade de toda sensação, ou de qualquer pensamento, é uma unidade inerente ao fenômeno. Essa crítica inviabiliza, portanto, uma psicologia reducionista, uma vez que a redução supõe as características inalteradas dos elementos.

Ao enfatizar dessa forma o aspecto mutante do Pensamento, James (1890/1952) cria para si o problema de explicar, então, porque o objeto é tratado como o mesmo. O que o associacionismo denomina simples, a impressão batizada ou idéia, é o "resultado de um processo de atenção discriminativa” (James, p. 146). A idéia de $a z u l$, por exemplo, é o resultado de uma série de experiências com coisas nas quais uma característica sensível específica é identificada como comum a todas elas, nesse caso de tonalidade, e à qual o sujeito aprende a designar por este nome, ignorando determinadas variações. Essa idéia - aparentemente simples - é apenas uma abstração e não um átomo de percepção utilizado para compor outras percepções. $\mathrm{O}$ azul não é uma propriedade que pode ser destacada da experiência com algo azul, sua descrição como uma idéia independente exige uma análise sobre a experiência complexa. $\mathrm{O}$ $A z u l$ é um conceito, um nome escolhido, por finalidades práticas $^{8}$, para figurar como o representante de todos os azuis, ele demarca uma relação mais intelectual que sensível.

\footnotetext{
${ }^{8}$ O benefício conseguido pela economia do nome implica a eliminação de todas as peculiaridades do objeto.
}

A grama do lado de fora da janela me parece o mesmo verde ao sol ou na sombra, mesmo que um pintor tivesse que pintar uma parte de amarelo brilhante e a outra de marrom escuro para alcançar o verdadeiro efeito sensível. (James, 1890/1952, p. 150).

O empirismo, na busca pelos elementos fundamentais da percepção, distancia-se da experiência em seu sentido mais estrito; procura na torre o fundamento do edifício. E é justamente ao radicalizar o próprio exame empírico, afastá-lo das armadilhas quotidianas, que James constrói sua crítica.

O debate de James (1890/1952) com o associacionismo não se esgota aqui. O problema agora é demonstrar a unidade entre os diversos pensamentos; isto é, mostrar que a passagem de um pensamento a outro, de uma idéia a outra, não é descontínua ou uma seqüência de elementos independentes; pelo contrário, ela é sensivelmente contínua, ou um fluxo.

\section{Substancialidade e Transitividade: A Unidade no Pensamento}

O principal desafio da formulação do Pensamento como fluxo é demonstrar que entre um pensamento e outro não há interrupção sensível; ou seja, que o Pensamento é um processo sensivelmente contínuo. Trata-se de apontar, novamente, a partir da própria análise dos fenômenos mentais uma unidade que subjaz a toda diversidade de pensamentos. Isto significa dizer que não há lapsos ou vazios no Pensamento, e nem tampouco saltos entre um pensamento e outro; isto é, o Pensamento não é uma seqüência de estados desconexos. Situações que poderiam ser interpretadas como descontinuidade são interrupções ou intervalos de tempo nos quais parece não haver atividade mental e, também, os casos em que há um contraste repentino de qualidade na percepção.

Quando se fala em intervalos de tempo nos quais não houve atividade mental, deve-se distinguir duas situações. Em primeiro lugar, há os casos em que a interrupção não é percebida. São desse tipo, por exemplo, algumas descrições de transe ou coma. O indivíduo não reconhece o intervalo porque para ele nada foi interrompido; a inferência de um período sem atividade mental é produto de uma observação externa, uma afirmação de um observador independente ${ }^{9}$. Nesses casos, como a tese do fluxo diz respeito apenas ao próprio Pensamento, considerar como interrupção algo de que a consciência não se deu conta é como esperar que o ouvido note um contraste entre cores (James, 1890/1952).

Há, contudo, as situações em que os intervalos são notados, como, por exemplo, o sono. Nesses casos, a análise envolve diversos fatores. Já no século XIX discutiam-se indícios que sugerissem a atividade mental durante o sono, como, por exemplo, o sonho, a capacidade de inferência do período em que se esteve dormindo e a própria habilidade de alguns indivíduos de programar a hora em que vão acordar. No entanto, segundo James (1890/1952), não há dados

\footnotetext{
9 Na descrição do paciente Greg F. (o "Último hippie" do livro Um antropólogo em Marte), o neurologista Oliver Sacks relata um episódio em que Greg refere-se a um show de rock que ocorrera há cerca de dez anos como tendo acontecido no ano anterior, ignorando completamente os outro nove anos; para ele, esse período simplesmente não havia acontecido.
} 
suficientes para uma afirmação definitiva ${ }^{10}$. O ponto central do argumento apresentado é a possibilidade de reconhecimento - pelo próprio Pensamento - de uma continuidade na atividade mental. O indivíduo lembra-se da hora de dormir, identifica seus pensamentos passados, reconhece os sonhos como próprios etc. "Essa comunidade do selfé algo que um intervalo de tempo não pode quebrar, e é por isso que um pensamento presente, mesmo consciente do intervalo, pode considerar-se contínuo com certas porções escolhidas do passado" (James, p. 155). Trata-se de afirmar a unidade entre os diversos pensamentos com base na coesão oferecida pela noção de self; isto é, recorrer à primeira característica: o pensamento tende a uma forma pessoal ${ }^{11}$.

O segundo ponto em questão, os "saltos" entre pensamentos, pode ser melhor ilustrado pelos casos em que ocorre uma mudança abrupta de qualidade no Pensamento; ou seja, uma ocasião em que um pensamento inicial é interrompido por um evento estranho e aquele que o segue parece não manter nenhuma relação com o primeiro, o que permitiria dizer que não há continuidade entre eles. Para ilustrar esse tipo de situação, imagine-se, por exemplo, a leitura deste tex to sendo interrompida por um ruído intenso e abafado. O pensamento acerca das teses jamesianas é interrompido e, após alguns instantes, substituído pela imagem de um acidente de automóveis. A passagem descontínua e desconexa de um pensamento ou estado mental para o outro parece evidente - é como se houvesse, literalmente, um buraco entre um estado e outro. Segundo James (1890/ 1952), esse tipo de conclusão deve-se em parte a uma visão introspectiva superficial e, em parte, a uma confusão.

A visão introspectiva superficial toma o evento abrupto (o barulho da batida) como puro. Outra vez é preciso contextualizar a percepção. O simples fato de dizer que um evento foi abrupto, inesperado ou estrondoso já significa a descrição de uma relação. O barulho-que-assusta pode ser melhor descrito como: silêncio-interrompido-por-ruído-intenso-em-condições-inesperadas; provavelmente, os mesmos decibéis durante um show de rock passariam despercebidos. É interessante notar, neste ponto, a maneira pela qual se supõe a sucessão entre os dois estados. A sucessão dos estados é, tradicionalmente, descrita de tal forma que cada estado supostamente termina quando o outro começa (como se fossem uma seqüência de pontos em uma reta, cada um marcando seu espaço próprio sem contato com o outro). James (1890/1952) chama atenção para um tipo de encadeamento no qual um estado mental ainda mantém algo de si até ser incorporado pelo outro (como se ele servisse de pano de fundo para o outro durante alguns instantes). É como se o

\footnotetext{
${ }^{10}$ Ver capítulo VIII, particularmente p.130-132.

${ }^{11}$ Uma descrição pormenorizada desse ponto não pode ser feita nos limites deste artigo, mas é importante destacar que a continuidade entre os diferentes pensamentos vividos em momentos distintos será possível graças à identificação em cada um deles dos feelings de calor (warmth) e intimidade (intimacy) que estiveram presentes no momento em que foram vivenciados. O Pensamento reconhece essa marca da mesma forma que um proprietário identifica seu rebanho ao ver o seu sinal impresso no animal. É essa marca que alinhava ao longo do tempo os mais diversos momentos da vida de um sujeito, garantido um sentido de identidade pessoal apesar da constante transformação.
}

encadeamento de pensamentos fosse uma espécie de melodia, na qual cada nota executada seguisse vibrando por alguns instantes e, com isso, convivesse de alguma forma com a próxima nota ${ }^{12}$. O juízo sobre a experiência com dado evento (assustador, inesperado etc.) é, neste sentido, parecido com a sensação provocada pela melodia dependendo da sucessão entre as notas; ele depende de sua relação com os outros estados. Pode-se observar, como explicitado na crítica da sensação, em um sentido mais amplo o aspecto relacional ou contextual de todo pensamento. Essa crítica é retirada da própria identificação da continuidade que é atestada pelas condições nas quais o predicado (assustador, surpreendente etc.) é atribuído, o feeling do barulho da batida é também "o feeling do silêncio que é interrompido" (p. 156).

A confusão diz respeito à equivalência entre o pensamento e a realidade "externa" que ele revela; mais especificamente, trata-se de uma interpretação do pensamento como um espelho dos acontecimentos do mundo externo mais uma vez, é estabelecida a distinção destacada na seção anterior. No referido exemplo, provavelmente entre a interrupção da leitura e a constatação da causa do barulho poder-se-ia notar um estado intermediário, um "susto”. O propósito de James (1890/1952) é mostrar como essa reação, embora constantemente negligenciada, é um estado mental absolutamente específico. Um evento surpreendente ocasiona uma série de respostas de alerta como, por exemplo, dilatação nas pupilas, prontidão do aparelho auditivo, aumento da freqüência cardíaca etc.; isto é, há uma relação direta do estado com aquilo que o ocasionou, em termos de sua adequação a fins específicos, como, por exemplo, correr. Dizer que há dois eventos desconexos é fazer a descrição do ponto de vista de um encadeamento externo de eventos, ou melhor, a partir de um observador externo. A surpresa provocada pelo barulho - ou a transição entre os dois momentos - é uma interrupção para o pensamento como uma cachoeira o é para o curso de um rio.

Com base no modo pelo qual se toma contato com o pensamento, é possível distinguir, a partir dessa análise, dois aspectos da vida mental denominados, respectivamente, de partes substantivas e partes transitivas ${ }^{13}$. No exemplo em questão, poder-se-ia colocar entre o momento da leitura e a identificação da fonte do barulho uma espécie de transição entre os dois, cuja peculiaridade é não apresentar nenhuma característica estável, apenas um tipo de conhecimento que é identificado por um feeling. A identificação dessa continuidade no Pensamento sugere, portanto, uma outra metáfora, que não a de uma cadeia ou seqüência de elementos justapostos.

\footnotetext{
${ }^{12}$ Essa também é a maneira pela qual James (1890/1952) propõe a sucessão dos estados cerebrais: uma determinada área, quando estimulada, continua ainda excitada quando outra área recebe estimulação.

${ }^{13}$ James compara os movimentos no fluxo do Pensamento com os de um pássaro: as transições são os pontos de vôo (places of flight) e as partes substantivas os locais de descanso (resting-places). A oposição se dá entre a estabilidade dos momentos de descanso e a dinâmica dos vôos. Durante os momentos de descanso, a maneira pelo qual se toma contato com o animal permite que se reflita sobre suas características, sua origem, coloração etc. já no vôo, a velocidade das mudanças oferece um contato bem menos estável com tal objeto o que não permite essas operações intelectuais.
} 
'Um 'rio' ou um 'fluxo' (stream) é a metáfora pela qual ela é mais naturalmente descrita. Ao falar sobre isso daqui em diante, vamos chamá-lo de fluxo do pensamento, da consciência ou da vida subjetiva" (James, 1890/1952, p. 155).

A diferenciação dos dois aspectos do fluxo pode ser entendida por formas distintas de conhecimento relacionadas a eles: knowledge-about e knowledge of acquaintance. Grosso modo, essas expressões poderiam ser traduzidas em um $\mathrm{Co}^{-}$ nhecimento sobre algo e em uma familiaridade ${ }^{14}$ com determinado objeto. O conhecimento sobre é aquele que consiste na descrição de suas relações; o sentido de cognição, neste caso, é uma operação do pensamento sobre determinado objeto. $\mathrm{O}$ aspecto descritivo chama a atenção para uma ligação com a linguagem: descrever relações significa enunciá-las. Em contrapartida, a familiaridade é o conhecimento preso ao momento e que, aparentemente, não precisa ser enunciado.

Eu conheço a cor azul quando a vejo; conheço o gosto da pêra quando a experimento ... mesmo que não seja capaz de dizer nada sobre a natureza dessas coisas. . . . Eu não posso comunicar (impart) esse conhecimento a ninguém que não tenha feito essas coisas. (James, 1890/ 1952, p. 144).

Ou seja, não é possível comunicar o azul a quem não tenha visto a cor, ou explicar o gosto da pêra a quem nunca a tenha provado. Em resumo:

Aquilo com que nos familiarizamos é apenas presente para nossa mente, nós o temos (have it), ou a idéia disso. Mas quando sabemos sobre isto, nós fazemos mais que meramente têlo; nós parecemos, ao pensar sobre suas relações, submetêlo a uma espécie de tratamento e operar sobre ele com nosso pensamento. (James, 1890/1952, p. 144).

A distinção estabelecida nessa passagem contrapõe a instantaneidade da familiaridade à estabilidade do conhecimento sobre.

Esse trecho permite retomar a distinção entre pensamento e feeling feita anteriormente. Uma das principais virtudes do termo pensamento seria uma referência quase que automática à cognição. A suposta inadequação do termo para referir-se a determinados estados atuais culminou no uso de um outro termo, feeling. Essa distinção diz respeito ao tipo de conhecimento em questão. Pensamento parece mais adequado a um conhecimento sobre, e feeling a uma familiaridade. "Os feelings são os germes ou pontos de partida da cognição, os pensamentos são a árvore desenvolvida" (James 1890/1952, p. 144). No limite, a oposição parece dar-se pela presença ou ausência de reflexão (da capacidade de operar sobre o conteúdo do pensamento).

James (1890/1952) atribui a ausência de qualquer menção à transição na maioria das explicações psicológicas a uma dificuldade de observação introspectiva desse tipo de estado. Não há ao que se apegar de forma reflexiva (não é possível que o pensamento opere sobre ele), e a presença de um novo estado substantivo parece suprimir o feeling da

\footnotetext{
${ }^{14}$ Quando, por exemplo, se diz que não se tem certeza sobre determinada conclusão, mas a idéia "soa familiar".
}

transição; ou seja, o conhecimento da transição parece desaparecer completamente uma vez que a transição tenha sido efetuada. Essas características parecem criar um problema para o conhecimento desse tipo de estado mental.

Se elas [as transições] são vôos para conclusões, interrompê-las para observá-las antes que a conclusão seja alcançada é realmente aniquilá-las. Por outro lado, se esperamos até que a conclusão seja atingida, ela as excede tanto em vigor e estabilidade que quase que as ofusca e engole sob seu brilho ... não se pode acender a luz rápido o bastante para ver como é a escuridão. (James, 1890/1952, p. 158).

Essa discussão indica a inadequação do conhecimento sobre como único critério de conhecimento, mas ao mesmo tempo levanta um problema acerca da relação entre as transições ou a forma pela qual elas são conhecidas - e a possibilidade de sua descrição. James (1884/1983b) afirma que só é possível falar sobre dado estado transitivo depois que ele aconteceu e, inevitavelmente, essa descrição é feita de outro contexto, ela já é outro estado mental: "o estado de consciência atual quando eu digo 'sinto-me cansado', não é o feeling direto de cansaço ... é o feeling de dizer-que-me-sinto-cansado..." (James, p. 143). Essa é base das ressalvas feitas à introspecção enquanto método de investigação na Psicologia, pois ela é ineficaz para apreender a transição como tal e acaba, por conta dessa dificuldade, negligenciado esse aspecto da atividade mental.

A dificuldade em reconhecer as transições parece ser acentuada por uma determinada concepção de linguagem. Para James (1890/1952), a maneira pela qual os empiristas tratam da linguagem acarreta alguns problemas. Em primeiro lugar, a suposição de que "onde houvesse um nome separado, uma coisa separada devia corresponder-lhe" (James, p. 159), negando, com isso, "a existência de entidades abstratas, princípios, e forças” (James, p. 159). Outro problema é a questão da nomeação como atributo da existência, isto é, se algo não tem nome, não existe.

Todos os estados psíquicos anônimos e ocultos foram, graças a esse erro, suprimidos; ou, se reconhecidos de alguma maneira, foram nomeados depois da percepção substantiva para a qual eles conduziram, como pensamentos 'sobre' este ou aquele objeto, a impassível palavra sobre suprimindo todas as suas delicadas idiossincrasias em seu som monótono. ${ }^{15}($ James, 1890/1952, p.159).

Esse argumento torna-se mais significativo quando James enfatiza que grande parte da atividade mental é constituída por esse tipo de estado, como, por exemplo, a expectativa criada por expressões de alerta: olhe! Pare! Espere!; pela tentativa de lembrar algo e se deparar com o fato de que, apesar da incapacidade de enunciar a palavra a ser lembrada, as alternativas incorretas são rejeitadas sem nenhuma hesitação.

É possível notar, portanto, como o estabelecimento das partes transitivas da atividade mental possibilita a utiliza-

\footnotetext{
${ }^{15}$ Novamente, é como se as exigências práticas desviassem a atenção das sutilezas da percepção.
} 
ção da metáfora de um fluxo para descrevê-la, em vez de uma cadeia de elementos independentes. Isso graças ao papel das transições para o reconhecimento da continuidade do Pensamento mesmo em situações que aparentavam descontinuidade. A inclusão dos estados transitivos tem duas conseqüências significativas para a psicologia de William James - e, posteriormente, para sua filosofia (McDermott, 1976). Em primeiro lugar, são as transições que asseguram a consistência conceitual da metáfora do fluxo e, com isso, a coerência do projeto alternativo às psicologias tradicionais, particularmente ao associacionismo. Mas, além disso, abre um novo horizonte para a definição do próprio objeto da Psicologia incluindo aquilo que escapa ao exercício introspectivo menos acurado. No entanto, é a necessidade de proporcionar objetividade à maneira pela qual se toma contato com os estados transitivos que oferece um novo desafio para a psicologia jamesiana.

\section{Conclusão}

A partir da crítica às sensações como elementos basilares dos estados mentais, James (1890/1952) argumenta contra a possibilidade desse tipo de explicação sintética na Psicologia. Ao contextualizar não só a sensação, mas todo pensamento, ele evidencia a impossibilidade de estabelecer os elementos simples que formariam os estados complexos. Conceitualmente, a conseqüência dessa crítica é um projeto que evita uma série de dificuldades teóricas - já que não é preciso explicar como se relaciona aquilo que não pode ser dado separadamente. Em termos metodológicos, afasta o reducionismo de sua psicologia, ao afirmar que a complexidade não pode ser reduzida a uma mera composição de elementos mais simples e, portanto, deve ser descrita enquanto complexidade. Uma disciplina que se ocupe desse universo deve ser capaz de tratar objetivamente essa complexidade sem eliminar suas idiossincrasias.

A tentativa de entender a vida mental como um fluxo de pensamento tem por finalidade, também, superar a dificuldade da unidade na vida mental, sem recorrer, evidentemente, a um princípio que transcenda a própria experiência do pensamento. É justamente tal dificuldade que a noção de fluxo pretende superar: se é possível estabelecer a continuidade dentro do próprio Pensamento, a unidade está intrinsecamente garantida. Tal continuidade é conseguida por meio do reconhecimento dos estados mentais transitivos. Esses estados, ao mesmo tempo que garantem a consistência teórica da psicologia jamesiana, sinalizam para o alargamento da própria noção de pensamento e, conseqüentemente, do próprio objeto da Psicologia. Neste sentido, é possível notar como o esforço empreendido por James (1890/ 1952, 1884/1983b) na análise conceitual traz conseqüências práticas diretas para a disciplina.

Essa experiência da transição - já que o estado não é meramente um postulado teórico, mas uma experiência do pensamento - será, também, um dos pontos centrais para o desenvolvimento da doutrina do Empirismo Radical de William James (McDermott, 1976), marcando aqui uma relação direta entre sua psicologia e o desenvolvimento posterior de sua obra propriamente filosófica. No entanto, apesar das contribuições dos estados transitivos para o pro- jeto geral - e também por causa delas - a compreensão do tipo de conhecimento relacionado aos estados transitivos guarda talvez uma das principais dificuldades da obra do autor norte-americano: como caracterizar de forma objetiva esse tipo de conhecimento? Um feelingé um estágio inicial de um conhecimento, que possibilitará em algum momento um conhecimento sobre, ou é a única forma possível de contato com determinados objetos? Se a última hipótese for verdadeira, será possível conceber uma linguagem que seja adequada à dinâmica de um conhecimento do que é pura transição, uma linguagem que permita falar sobre os feelings? Ou eles são o ponto inacessível da subjetividade? Mais uma vez, a consistência do projeto jamesiano e o sucesso prático de uma psicologia construída a partir dessa orientação dependem de uma resposta satisfatória a essas questões, respostas estas que, felizmente, ultrapassam as possibilidades deste artigo, já que “a melhor marca de saúde que uma ciência pode mostrar é sua face inacabada” (James, 1890/1952, p. xiv).

\section{Referências}

Giorgi, A. (1992). A phenomenological reinterpretation of the jamesian schema for psychology. In M. E. Donnelly (Ed.), Reinterpreting the legacy of William James (pp. 119-136). Washington, DC: American Psychological Association.

Heidbreder, E. (1975). Psicologias do século XX (L. S. Blandy, Trad.). São Paulo, SP: Mestre Jou. (Original publicado em 1933)

Hobbes, T. (1974). Leviatã (J. P. Monteiro \& M. B. N. da Silva, Trads.). In Coleção os pensadores. São Paulo, SP: Abril Cultural. (Original publicado em 1651)

James, W. (1952). The principles of psychology. In Britannica great books of the western world. Chicago: Chicago University Press. (Original publicado em 1890)

James, W. (1976). Essays in radical empiricism. Cambridge, MA: Harvard University Press. (Original publicado em 1912)

James, W. (1983a). Are we automata? In F. Burkhardt \& F. Bowers (Eds.), Essays in Psychology (pp. 38-61). Cambridge, MA Harvard University Press. (Original publicado em 1879)

James, W. (1983b). On some omissions of introspective psychology. In F. Burkhardt \& F. Bowers (Eds.), Essays in Psychology (pp. 142-167). Cambridge, MA: Harvard University Press. (Original publicado em 1884)

James, W. (1983c). Talks to teachers on Psychology. Cambridge, MA: Harvard University Press. (Original publicado em 1899)

James, W. (1998). Pragmatism. In Pragmatism and The meaning of truth (pp. 1-166). Cambridge, MA: Harvard University Press. (Original publicado em 1909)

Locke, J. (1973). Ensaio acerca do entendimento humano (A. Aiex, Trad.). In Coleção os pensadores. São Paulo, SP: Abril Cultural. (Original publicado em 1706)

McDermott, J. J. (1976). Introduction. In F. Burkhardt \& F. Bowers (Eds.), Essays in radical empiricism (pp. xi-xlviii). Cambridge, MA: Harvard University Press.

Myers, G. E. (1992). William James and contemporary Psychology. In M. E. Donnelly (Ed.), Reinterpreting the legacy of William James (pp. 49-64). Washington, DC: American Psychological Association. 